\title{
Myocardial protective and anti-inflammatory effects of dexmedetomidine in patients undergoing cardiovascular surgery with cardiopulmonary bypass: a systematic review and meta-analysis
}

\author{
Milian Chen ${ }^{1}\left(\mathbb{D} \cdot \mathrm{Xia}_{\mathrm{Li}}{ }^{1} \cdot \mathrm{Guo} \mathrm{Mu^{2 }}\right.$
}

Received: 9 May 2021 / Accepted: 27 July 2021 / Published online: 3 August 2021

(c) Japanese Society of Anesthesiologists 2021

\begin{abstract}
Cardiopulmonary bypass (CPB) technology provides potential for cardiac surgery, but it is followed by myocardial injury and inflammation related to ischemia-reperfusion. This meta-analysis aimed to systematically evaluate the cardioprotective effect of dexmedetomidine on cardiac surgery under CPB and its effect on accompanied inflammation. PubMed, Cochrane Library, EMBASE and Web of Science databases were comprehensively searched for all randomized controlled trials (RCTs) published before April 1st, 2021 that explored the application of dexmedetomidine in cardiac surgery. Compared with the control group (group C), the concentrations of CK-MB in the perioperative period and cTn-I at $12 \mathrm{~h}$ and $24 \mathrm{~h}$ after operation in dexmedetomidine group (group D) were significantly decreased $(P<0.05)$. In addition, in group $\mathrm{D}$, the levels of interleukin-6 at $24 \mathrm{~h}$ after operation, tumor necrosis factor-a at the $12 \mathrm{~h}$ and $24 \mathrm{~h}$ after operation were significantly decreased $(P<0.05)$. At the same time, the length of Intensive Care Unit stay in group D was significantly shorter than group $\mathrm{C}(P<0.05)$. However, there was no significant difference in interleukin-10 level, $\mathrm{C}$ reactive protein level, the time on ventilator and length of hospital stay between the two groups $(P>0.05)$. The application of dexmedetomidine in cardiac surgery with CPB can reduce CK-MB and cTn-I concentration and interleukin-6, tumor necrosis factor- $\alpha$ levels to a certain extent and shorten the length of Intensive Care Unit stay, but it has no significant effect on IL-10 level, C reactive protein level, the time on ventilator and length of hospital stay.
\end{abstract}

Keywords Dexmedetomidine $\cdot$ Myocardial protective $\cdot$ Anti-inflammatory effects $\cdot$ Cardiac surgery $\cdot$ Cardiopulmonary bypass

\section{Introduction}

Cardiopulmonary bypass (CPB) provides blood and oxygen to the body's organs and tissues when the heart stops working, allowing open-heart surgery to be performed successfully and maintaining the body's metabolism [1]. However, owing to the lack of blood supply to the heart during CPB,

Milian Chen, Xia Li and Guo Mu have contributed equally to this work.

Milian Chen

MilianChen.doctor@ outlook.com

1 Department of Anesthesiology, Shehong People's Hospital, NO. 19, Guanghan road, Shehong 629200, Sichuan, People's Republic of China

2 Department of Anesthesiology, Zigong Fourth People's Hospital, Zigong, Sichuan, People's Republic of China perioperative myocardial protection, which directly affects the recovery of cardiac function post-surgery, is very important [2]. Myocardial protection strategy refers to a variety of perioperative techniques used to reduce ischemia-reperfusion injury and prevent postoperative cardiac dysfunction $[3,4]$. The main method is to reduce myocardial oxygen demand, such as inducing lower body temperature and nonbeating heart. Besides, some drugs that provide myocardial protective effects are included too [5].

In addition to myocardial injury, the inflammatory response related to $\mathrm{CPB}$ is also one of the issues worthy of our concern in open-heart surgery. During CPB, the contact of patients' blood with tube system will produce a large number of inflammatory mediators, that can cause tissue and organ damage [6].

As a highly selective $\alpha_{2}$-adrenergic receptor agonist, dexmedetomidine can reduce the release of cytokines, inhibit 
inflammation response and alleviate ischemia-reperfusion injury, thus exerting its organ-protective effects [7, 8].

Some clinical studies have been implemented to explore whether there is a similar effect in cardiac surgery under CPB. Most of them have reported that the addition of dexmedetomidine can inhibit inflammation and provide myocardial protection $[9,10]$; however, the study by Tosun reported that myocardial damage was not reduced by the administration of dexmedetomidine [2]. In addition, there is a metaanalysis [11] that studied the myocardial protective effect of dexmedetomidine during cardiac surgery. However, it makes a comprehensive analysis of all types of cardiac surgery, fails to distinguish between CPB and non-CPB. Moreover, it is only limited to the changes of hemodynamics, and does not involve the detection of myocardial injury markers and inflammatory factors.

To solve these problems, this meta-analysis aimed to clarify whether dexmedetomidine can inhibit the inflammatory response, provide myocardial protection, and promote the recovery of patients by analyzing randomized controlled trials.

\section{Methods}

We conduct this meta-analysis according to the rules of Preferred Reporting Items for Systematic Reviews and MetaAnalyses (PRISMA) [12]. PRISMA is an evidence-based minimum set of items for reporting in systematic reviews and meta-analyses which can be used as a basis for reporting systematic reviews of different types of research.

\section{Literature search}

The PubMed, Cochrane Library, EMBASE and Web of Science databases were comprehensively searched for randomized controlled clinical trials (RCTs) published before April 2021 that investigated the application of dexmedetomidine in CPB or cardiac surgery. Additionally, the reference lists of all included studies were checked for any potential additional publications. The key words included dexmedetomidine, cardiopulmonary bypass, thoracic surgery, and cardiac surgical procedures. The detailed search strategies were presented in the Supplemental materials (Supplementary Table 1 Details about the search strategies).

\section{Inclusion and exclusion criteria}

The inclusion criteria for the studies were as follows:

(1) it was a randomized controlled trial; (2) the target population comprised patients undergoing cardiovascular surgery with CPB; (3) it compared dexmedetomidine with normal saline; (4) outcomes were related with cardiac function indicator(s), myocardial injury marker(s), inflammatory factor(s), and the length of hospital stay; and (5) the full text was available.

The exclusion criteria were as follows:

(1) it was a duplicate publication, review, editorial, abstract, comment, case report, animal study, or expert consensus/guidance; (2) surgery was not performed with CPB; and (3) research about pediatric cases.

\section{Data extraction}

Two reviewers independently screened the papers from their titles and abstracts and selected relevant studies met the eligibility criteria. Data were extracted and collated independently by the same two reviewers independently with any disagreement settled by a third reviewer. We sent e-mails to the original investigators when requisite data were lacking in the publications.

The following items were extracted: (1) basic information: name of the first author, publication date, sample size, demographic data of participants; (2) techniques: type of surgery, anesthesia method, perioperative medication, dose and administration rate of dexmedetomidine; (3)primary outcomes: the concentrations of creatine kinase-MB (CK$\mathrm{MB}$ ) and cardiac troponin I (cTn-I) at different time points; (4) secondary outcomes: the levels of interleukin-6 (IL-6), IL-10, tumor necrosis factor- $\alpha$ (TNF- $\alpha$ ) and $C$ reactive protein (CRP) at different time points, the time on ventilator, the length of Intensive Care Unit (ICU) stay and length of hospital stay.

\section{Statistical analysis}

The meta-analysis was conducted using Review Manager Software (Revman 5.4, Cochrane Collaboration, Oxford, United Kingdom). Continuous data was expressed by weighted mean difference (WMD) and 95\% confidence interval (CI). If the mean was too different or the unit of measurement was inconsistent, the data was expressed by standard Mean Difference (SMD) and 95\% CI. Cochran's $Q$ test and Higgins' $I^{2}$ statistical test were used to assess the statistical heterogeneity. The results showed low level of heterogeneity when $I^{2}<50 \%$, and a fixed-effects model would be used. The results showed significant heterogeneity when $I^{2} \geq 50 \%$, in which case a sensitivity analysis and subgroup analyses would be conducted to identify the source of heterogeneity. If the heterogeneity could not be eliminated, a random-effects model that estimated the uncertainty of results with sampling error and studies variance would be used. Descriptive analysis was used for data that cannot be merged. 
Risk of bias assessment was done using Cochrane Collaboration tool (Cochrane, London, UK). Finally, a funnel plot was used to visually assess the potential publication bias.

\section{Results}

\section{Search results and study characteristics}

A total of 1003 articles were retrieved, and 364 of them remained after excluding duplicate articles. Based on the title and abstract, 273 articles were excluded, leaving 91 articles. 82 articles were discarded for various reasons(retrospective study, review article, case report, expert consensus or guidance and so on) when the full text was browsed for further screening, and 9 studies [2, 7, 9, 10, 13-17] finally met the inclusion criteria(Fig. 1 Flow chart of study selection). The characteristics of the 9 studies involved 418 participants were summarized in Table 1 Characteristics of the included studies.

\section{Primary outcomes}

\section{CK-MB concentration}

The pooling results showed that the concentration of CK-MB between the two groups has no significant difference at these several time points individually, including 15 min after declamping the aorta, the end of operation, $24 \mathrm{~h}$ and $48 \mathrm{~h}$ after operation. However, the comprehensive results showed that the concentration of CK-MB in dexmedetomidine group (group D) was significantly lower than that of the control group (group C) (SMD 0.70; 95\% CI $0.16-1.25 ; P<0.05 ; I^{2}=91 \%$ ), which suggested a certain clinical significance. The meta-analysis results at the above time points showed heterogeneity. The sensitivity analysis and subgroup analysis failed to identify the source of heterogeneity, and a random-effects model was used for further analysis. (Fig. 2 CK-MB concentration).
Fig. 1 Flow chart of study selection

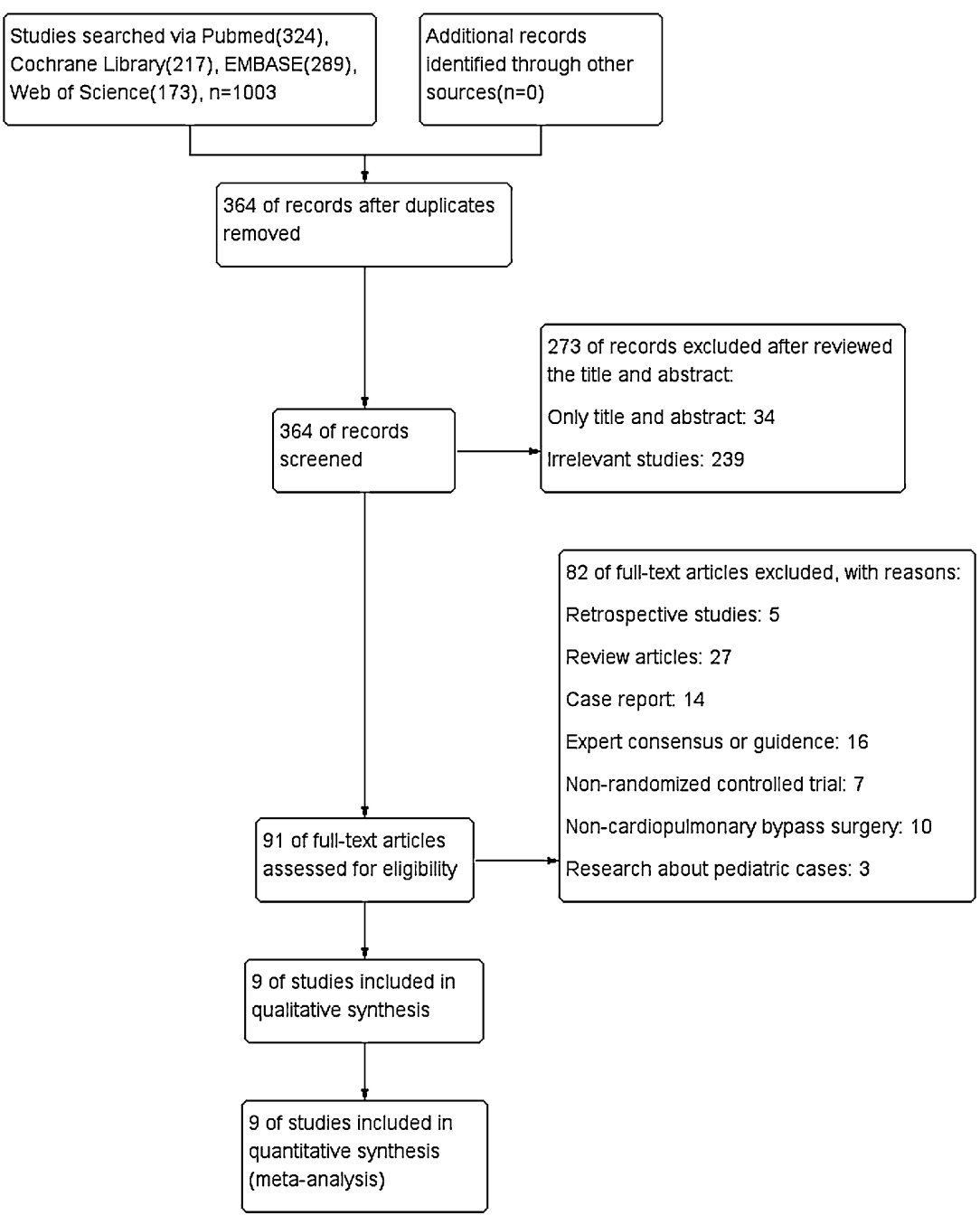




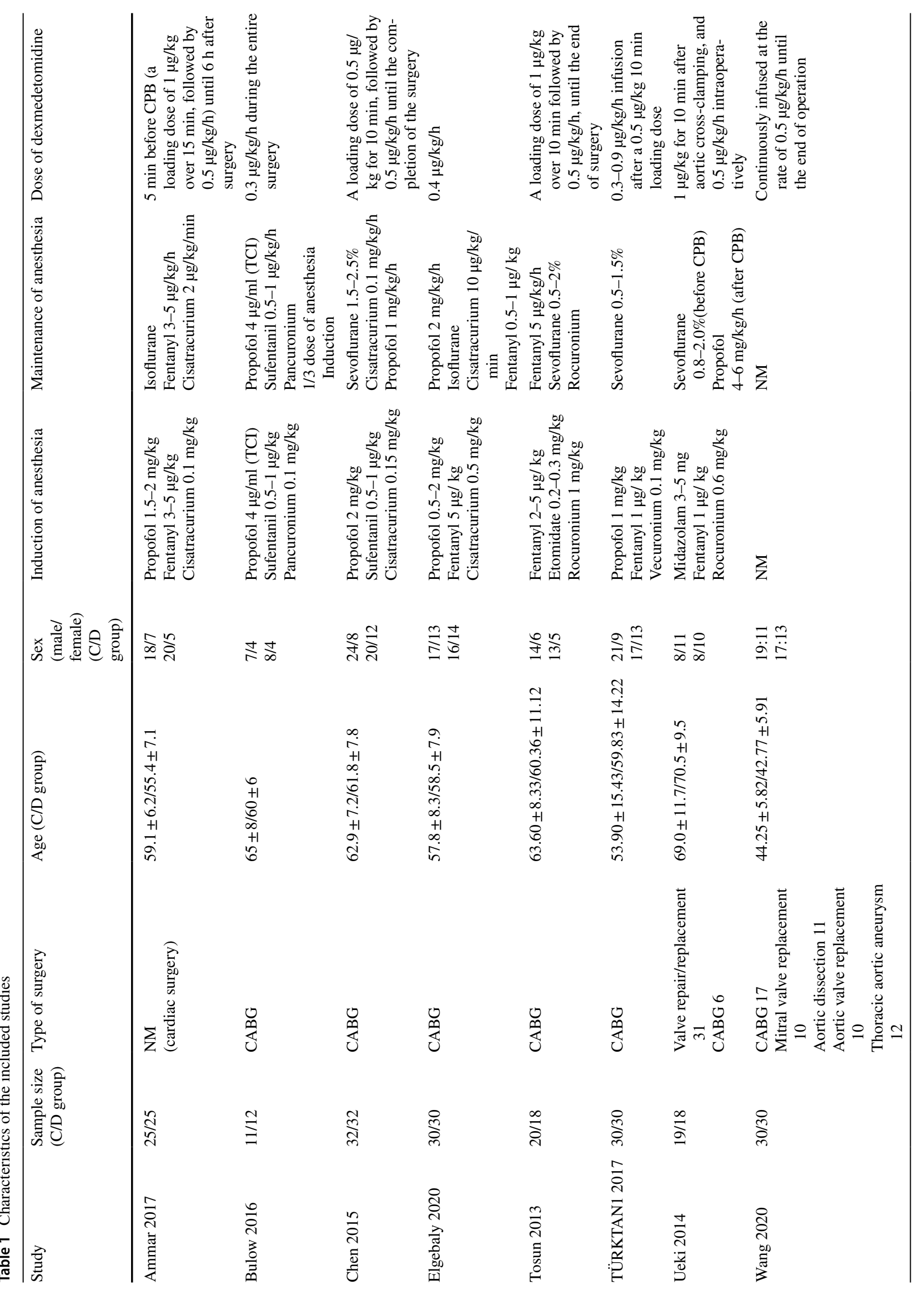




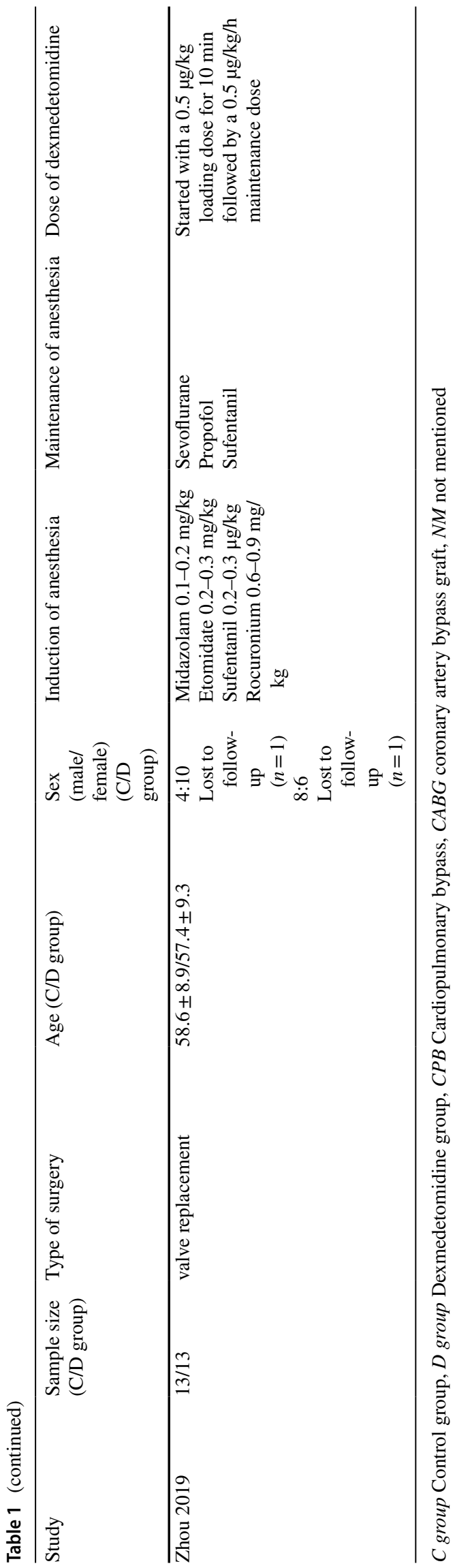

cTn-I concentration

Compared with the group C, cTn-I concentration in group $\mathrm{D}$ was significantly decreased at $12 \mathrm{~h}$ (SMD $3.62 ; 95 \% \mathrm{CI}$ $\left.3.00-4.24 ; P<0.05 ; I^{2}=0 \%\right)$ and $24 \mathrm{~h}$ (SMD 3.49; 95\% CI $\left.0.41-6.58 ; P<0.05 ; I^{2}=98 \%\right)$ after operation. However, no significant difference was found between the two groups at the time points of CPB in progress, $15 \mathrm{~min}$ after declamping the aorta, the end of operation and $48 \mathrm{~h}$ after operation. The sensitivity analysis and subgroup analysis failed to eliminate the heterogeneity, and a randomeffects model was used for further analysis. (Fig. $3 \mathrm{cTn}-\mathrm{I}$ concentration).

\section{Secondary outcomes}

\section{IL-6 levels}

The level of IL-6 at several time points including CPB in progress, $12 \mathrm{~h}$ and $24 \mathrm{~h}$ after operation was analyzed. The result showed the level of IL-6 in group D was lower than group C at $24 \mathrm{~h}$ (MD 37.47; 95\% CI 11.13-63.81; $P<0.05$; $\left.I^{2}=99 \%\right)$ after operation. No difference was found at other time points. A random-effect model was used to complete the analysis as the heterogeneity cannot be eliminated by sensitivity analysis and subgroup analysis. (Fig. 4 IL-6 levels).

\section{IL-10 levels}

The synthesized data showed that there was no significant difference between the two groups when it came to the level of IL-10 at $24 \mathrm{~h}$ after operation. (Fig. 5 IL-10 levels).

\section{TNF-a levels}

As shown in the result, the level of TNF- $\alpha$ in group D was lower at $12 \mathrm{~h}$ (SMD 2.92; 95\% CI 0.35-5.48; $P<0.05$; $\left.I^{2}=96 \%\right)$ and $24 \mathrm{~h}(\mathrm{SMD} 4.13 ; 95 \%$ CI $2.91-5.35 ; P<0.05$; $\left.I^{2}=71 \%\right)$ after operation when compared with group C. Sensitivity analysis and subgroup analysis failed to eliminate the heterogeneity, so a random-effect model was used. There was no obvious difference between the two groups at the time point of CPB in progress. (Fig. 6 TNF- $\alpha$ levels).

\section{CRP levels}

In terms of CRP, there was no significant difference between the two groups. A random-effect model was used as the 


\begin{tabular}{|c|c|c|c|c|c|c|c|c|c|c|c|}
\hline \multirow[b]{2}{*}{ Study or Subaroup } & \multicolumn{3}{|c|}{ Control } & \multicolumn{3}{|c|}{ Dexmedetomidine } & \multicolumn{2}{|r|}{ Std. Mean Difference } & \multirow{2}{*}{\multicolumn{3}{|c|}{$\begin{array}{l}\text { Std. Mean Difference } \\
\text { IV. Random. } 95 \% \mathrm{Cl}\end{array}$}} \\
\hline & Mean & SD & Total & Mean & SD & Total & Weight & IV. Random, $95 \% \mathrm{Cl}$ & & & \\
\hline \multicolumn{12}{|c|}{ 5.1.1 15 minutes after declamping the aorta } \\
\hline Chen 2015 & 95.81 & 18.86 & 32 & 44.81 & 9.85 & 32 & $6.4 \%$ & $3.35[2.57,4.12]$ & & & \\
\hline Elgebaly 2020 & 11.75 & 7.6 & 30 & 9.77 & 2.6 & 30 & $6.9 \%$ & $0.34[-0.17,0.85]$ & & & \\
\hline Türktan 2017 & 27.54 & 19.56 & 30 & 41.88 & 60.24 & 30 & $6.9 \%$ & $-0.32[-0.83,0.19]$ & & & \\
\hline Subtotal $(95 \% \mathrm{Cl})$ & & & 92 & & & 92 & $20.2 \%$ & $1.10[-0.77,2.97]$ & & & \\
\hline \multicolumn{12}{|c|}{ Heterogeneity: $\mathrm{Tau}^{2}=2.64 ; \mathrm{Chi}^{2}=61.86, \mathrm{df}=2(\mathrm{P}<0.00001) ; \mathrm{I}^{2}=97 \%$} \\
\hline \multicolumn{12}{|c|}{ 5.1.2 the end of operation } \\
\hline Ammar 2017 & 43.2 & 9.6 & 25 & 40.8 & 8.6 & 25 & $6.8 \%$ & $0.26[-0.30,0.82]$ & & & \\
\hline Elgebaly 2020 & 19.55 & 6.6 & 30 & 11.75 & 7.6 & 30 & $6.8 \%$ & $1.08[0.54,1.63]$ & & & \\
\hline Ueki 2014 & 40.9 & 15.2 & 19 & 43.9 & 16.5 & 18 & $6.7 \%$ & $-0.19[-0.83,0.46]$ & & & \\
\hline Subtotal $(95 \% \mathrm{Cl})$ & & & 74 & & & 73 & $20.3 \%$ & $0.40[-0.32,1.12]$ & & & \\
\hline \multicolumn{12}{|c|}{ Heterogeneity: $\mathrm{Tau}^{2}=0.32 ; \mathrm{Chi}^{2}=9.34, \mathrm{df}=2(\mathrm{P}=0.009) ; \mathrm{I}^{2}=79 \%$} \\
\hline \multicolumn{12}{|c|}{ Test for overall effect: $Z=1.08(P=0.28)$} \\
\hline \multicolumn{12}{|c|}{ 5.1.3 24h after operation } \\
\hline Ammar 2017 & 40.7 & 11.1 & 25 & 30.2 & 9.9 & 25 & $6.8 \%$ & $0.98[0.39,1.57]$ & & & \\
\hline Bulow 2016 & 46.92 & 5.25 & 11 & 72.47 & 23.18 & 12 & $6.0 \%$ & $-1.43[-2.37,-0.50]$ & & & \\
\hline Chen 2015 & 94.71 & 19.71 & 32 & 50.14 & 8.14 & 32 & $6.5 \%$ & $2.92[2.20,3.64]$ & & & \\
\hline Elgebaly 2020 & 25.75 & 2.6 & 30 & 15.75 & 5.6 & 30 & $6.6 \%$ & $2.26[1.60,2.92]$ & & & \\
\hline Tosun 2013 & 40.12 & 28.09 & 20 & 35.27 & 23.94 & 18 & $6.7 \%$ & $0.18[-0.46,0.82]$ & & & \\
\hline Ueki 2014 & 30.5 & 20 & 19 & 26.9 & 11.1 & 18 & $6.7 \%$ & $0.22[-0.43,0.86]$ & & & \\
\hline Subtotal $(95 \% \mathrm{Cl})$ & & & 137 & & & 135 & $39.3 \%$ & $0.87[-0.24,1.98]$ & & & \\
\hline \multicolumn{12}{|c|}{ Heterogeneity: $\mathrm{Tau}^{2}=1.80 ; \mathrm{Chi}^{2}=79.72, \mathrm{df}=5(\mathrm{P}<0.00001) ;\left.\right|^{2}=94 \%$} \\
\hline \multicolumn{12}{|c|}{ Test for overall effect: $Z=1.54(P=0.12)$} \\
\hline \multicolumn{12}{|c|}{ 5.1.4 48h after operation } \\
\hline Ammar 2017 & 16.5 & 3.7 & 25 & 15 & 2.6 & 25 & $6.8 \%$ & $0.46[-0.10,1.02]$ & & & \\
\hline Tosun 2013 & 24.01 & 14.48 & 20 & 24.39 & 16.3 & 18 & $6.7 \%$ & $-0.02[-0.66,0.61]$ & & & \\
\hline Ueki 2014 & 17.8 & 7.4 & 19 & 14.5 & 5.7 & 18 & $6.6 \%$ & $0.49[-0.17,1.14]$ & & & \\
\hline Subtotal $(95 \% \mathrm{Cl})$ & & & 64 & & & 61 & $20.1 \%$ & $0.32[-0.04,0.67]$ & & & \\
\hline \multirow{2}{*}{\multicolumn{12}{|c|}{$\begin{array}{l}\text { Heterogeneity: } \mathrm{Tau}^{2}=0.00 ; \mathrm{Chi}^{2}=1.62, \mathrm{df}=2(P=0.45) ; \mathrm{I}^{2}=0 \% \\
\text { Test for overall effect: } Z=1.76(P=0.08)\end{array}$}} \\
\hline & & & & & & & & & & & \\
\hline Total $(95 \% \mathrm{Cl})$ & & & 367 & & & 361 & $100.0 \%$ & $0.70[0.16,1.25]$ & & & \\
\hline \multicolumn{9}{|c|}{ Heterogeneity: $\mathrm{Tau}^{2}=1.06 ; \mathrm{Chi}^{2}=163.40, \mathrm{df}=14(P<0.00001) ; \mathrm{I}^{2}=91 \%$} & & & 4 \\
\hline Test for overall effect: & $Z=2.52$ & $(P=0.0$ & & & & & & & -2 & Control Dexmed & nidine \\
\hline
\end{tabular}

Fig. 2 CK-MB concentration

heterogeneity cannot be eliminated by sensitivity analysis and subgroup analysis. (Fig. 7 CRP levels).

\section{Time on ventilator, length of ICU stay, and hospital stay}

A total of 5 studies, 231 cases involved the time on ventilator. The results showed that the use of dexmedetomidine in the operation cannot shorten the time of patients on ventilator (MD $1.91 ; 95 \% \mathrm{CI}-0.14$ to $3.95 ; P>0.05 ; I^{2}=78 \%$ ).

(Fig. 8 The time on ventilator).

The length of ICU stay, was shown in 5 studies, involving 231 cases, and better outcome was shown in group D (MD 0.66; 95\% CI 0.55-0.77; $P<0.05 ; I^{2}=0 \%$ ). (Fig. 9 The length of ICU stay).
The length of hospital stay was recorded in 3 studies including 133 patients. The results showed that there was no significant difference between the two groups (MD -0.20 ; 95\% CI: -2.46 to $2.05 ; P>0.05 ; I^{2}=86 \%$ ). (Fig. 10 The length of hospital stay).

\section{Bias assessment}

We can learn from the risk of bias graph (Fig. 11 Risk of bias graph), one study [17] had high risk for attrition bias, while other studies have not found any high risk items. As for the publication bias, slight asymmetry can be found in the funnel plot, so we concluded that there was possibility of publication bias. (Fig. 12 Funnel plot). 


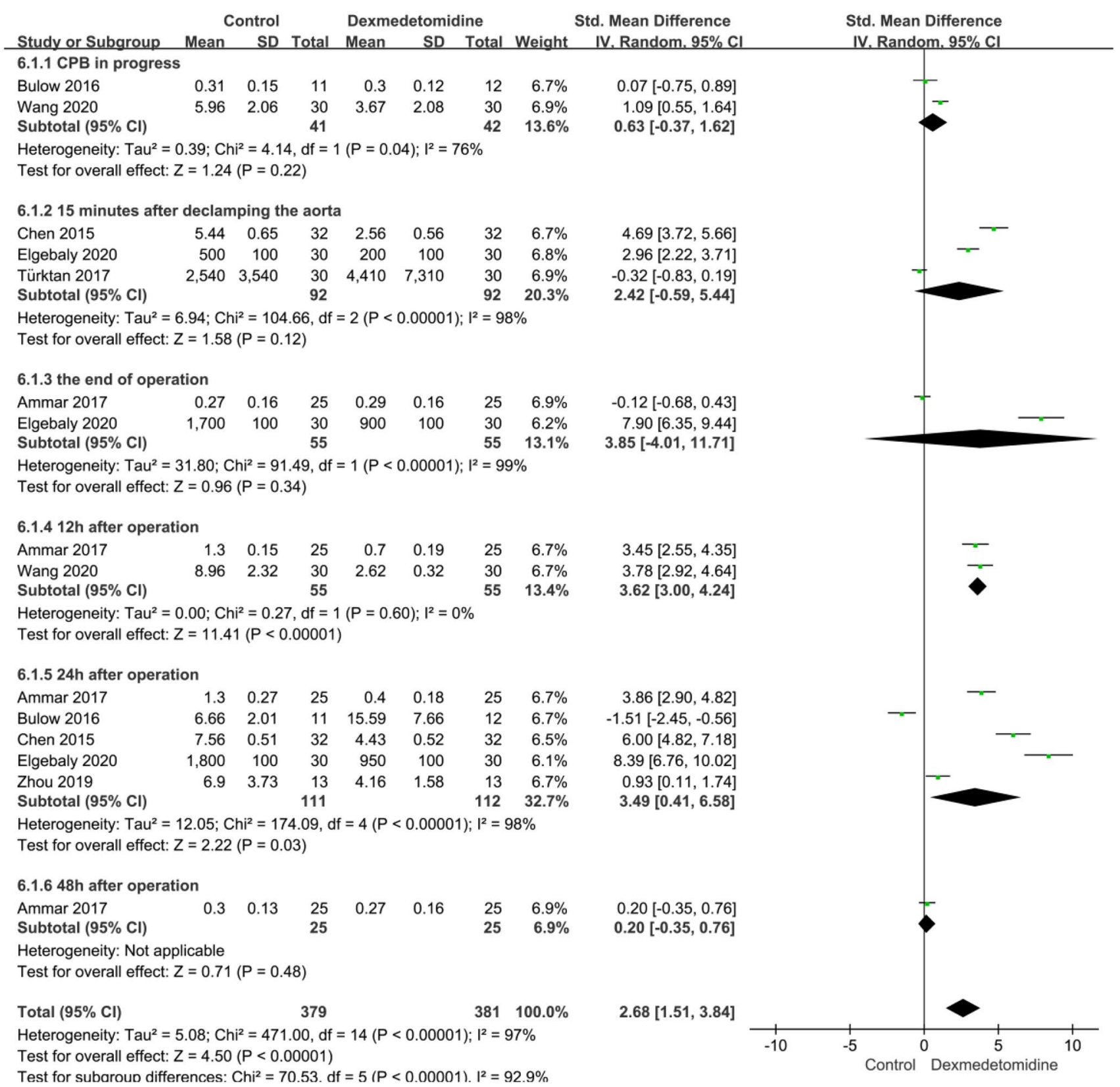

Fig. 3 cTn-I concentration

\section{Discussion}

Cardiac surgery with the CPB procedure is associated with ischemia/reperfusion injury, which is closely related to reversible postischemic cardiac dysfunction and irreversible myocardial cell death [18]. Therefore, CPB surgery requires a series of measures to provide myocardial protection, aimed at reducing oxygen consumption of myocardial cells so as to adapt cardiomyocytes to transient ischemia. Inflammatory response results from tissue reperfusion injury, and is also the primary cause of ischemia-reperfusion injury [19]. Dexmedetomidine 


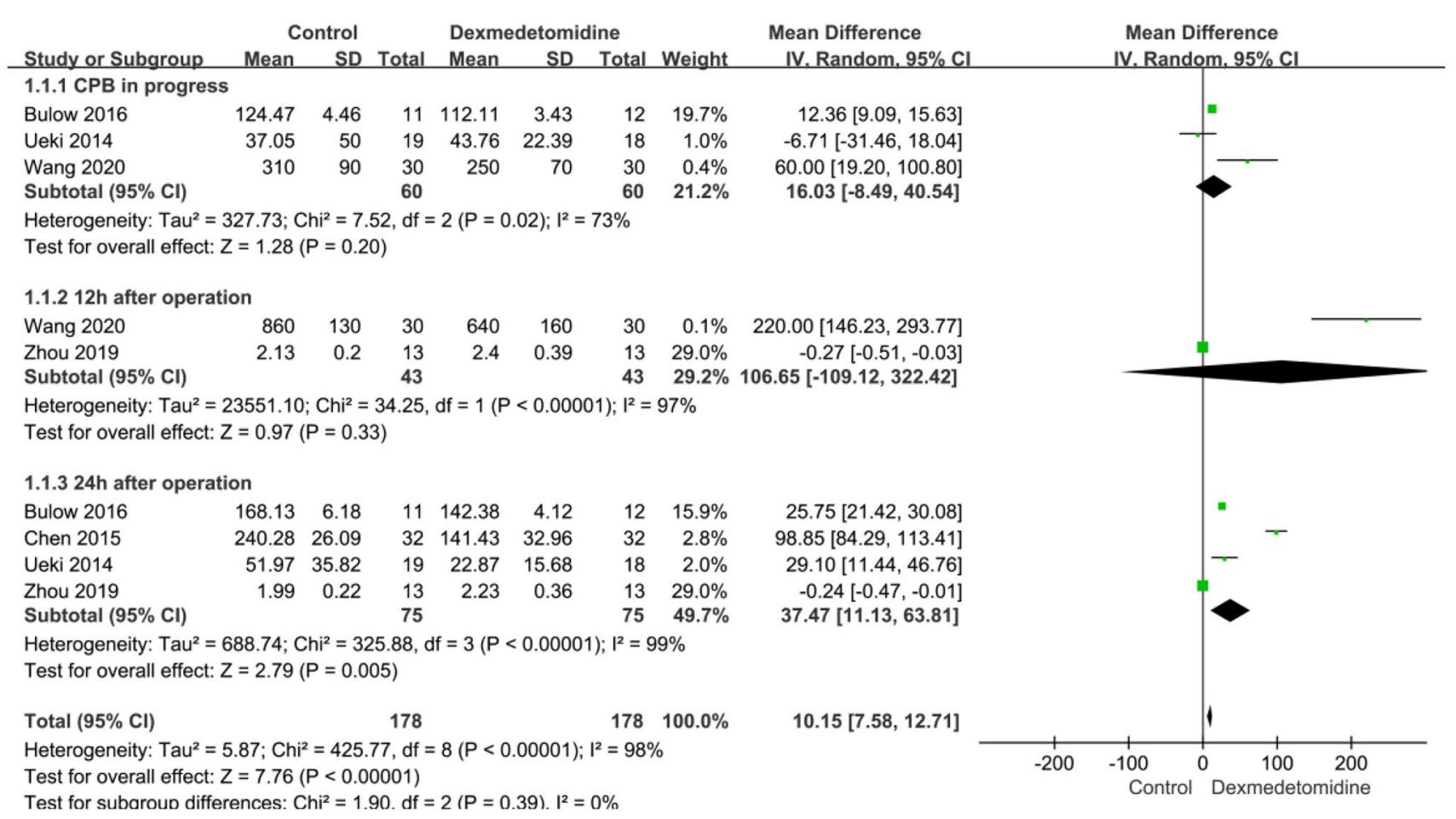

Fig. 4 IL-6 levels

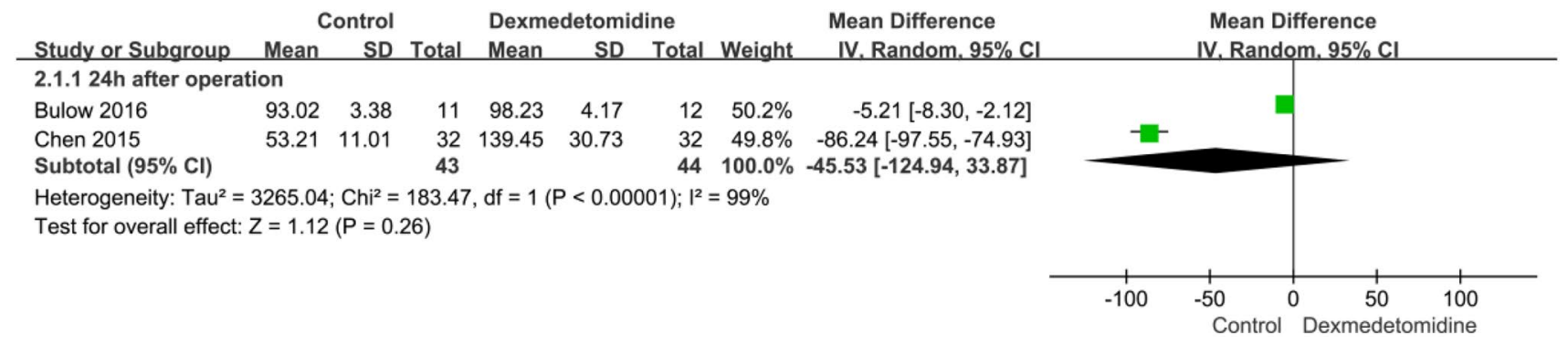

Fig. 5 IL-10 levels

has been investigated in many studies because it can reduce the release of cytokines, inhibit the inflammatory response, reduce ischemia-reperfusion injury, and thereby contribute to organ protection [20-22]. In the related research involved in this meta-analysis, a loading dose of $0.5-1.0 \mu \mathrm{g} / \mathrm{kg}$ for $10-15 \mathrm{~min}$, followed by the maintenance dose of $0.3-0.5 \mu \mathrm{g} / \mathrm{kg} / \mathrm{h}$ until the completion of the surgery was the main dosage and timing of administration of dexmedetomidine.

The level of CK-MB and cTn-I can be used to judge the condition of myocardial injury, and its dynamic changes often provide a more meaningful reference $[23,24]$. The result of this meta-analysis showed that the addition of dexmedetomidine can significantly reduce the levels of CK-MB and cTn-I, but the level of cTn-I on the $48 \mathrm{~h}$ after operation was comparable between the two groups, which suggested that dexmedetomidine may have a certain myocardial protective effect in the early postoperative period.

In addition to the effect on markers of myocardial injury, dexmedetomidine also inhibited the intensity of inflammatory response. The results showed that dexmedetomidine decreased the levels of pro-inflammatory cytokines IL-6 and TNF- $\alpha$ during CPB procedure, but there was no significant 


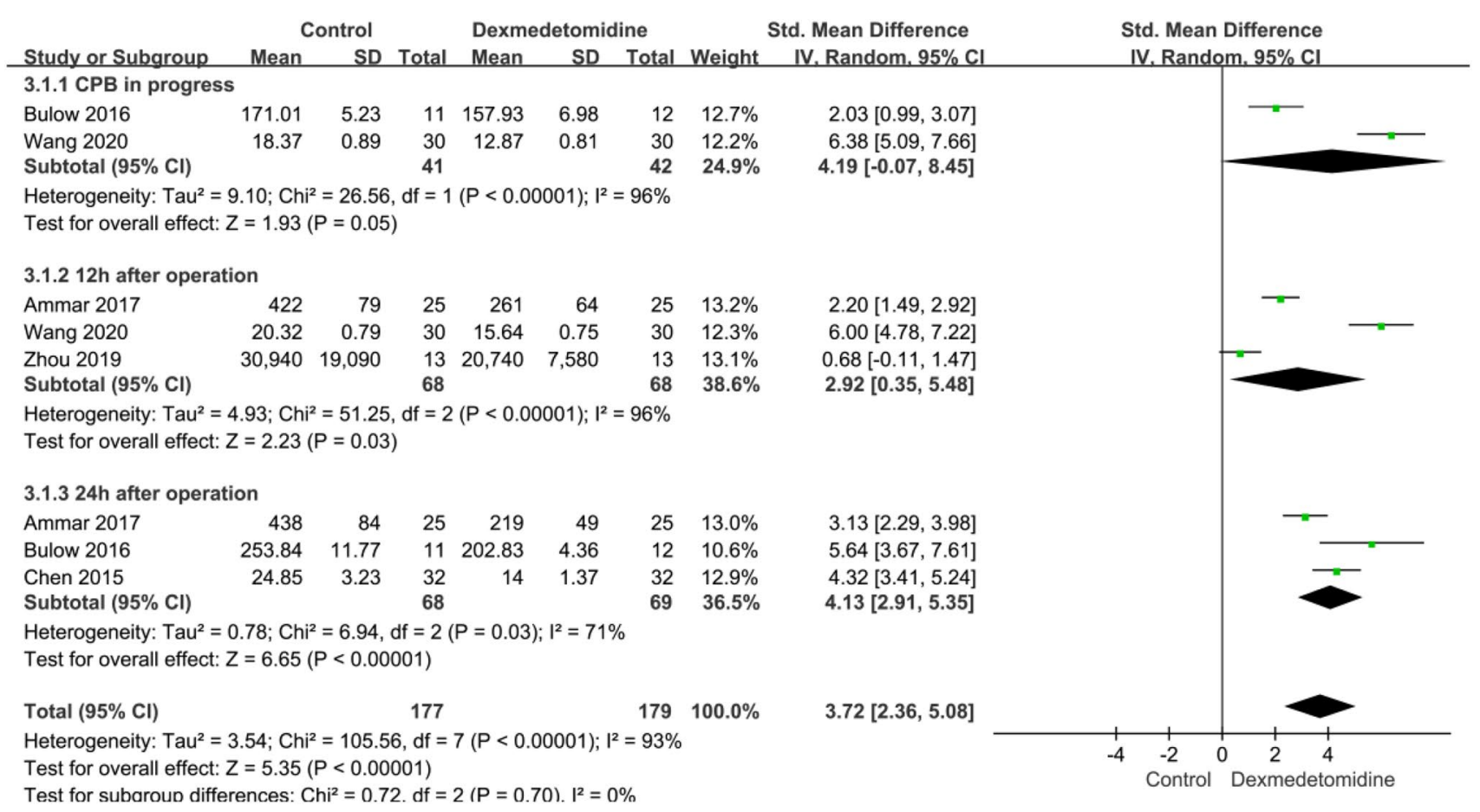

Fig. 6 TNF- $\alpha$ levels

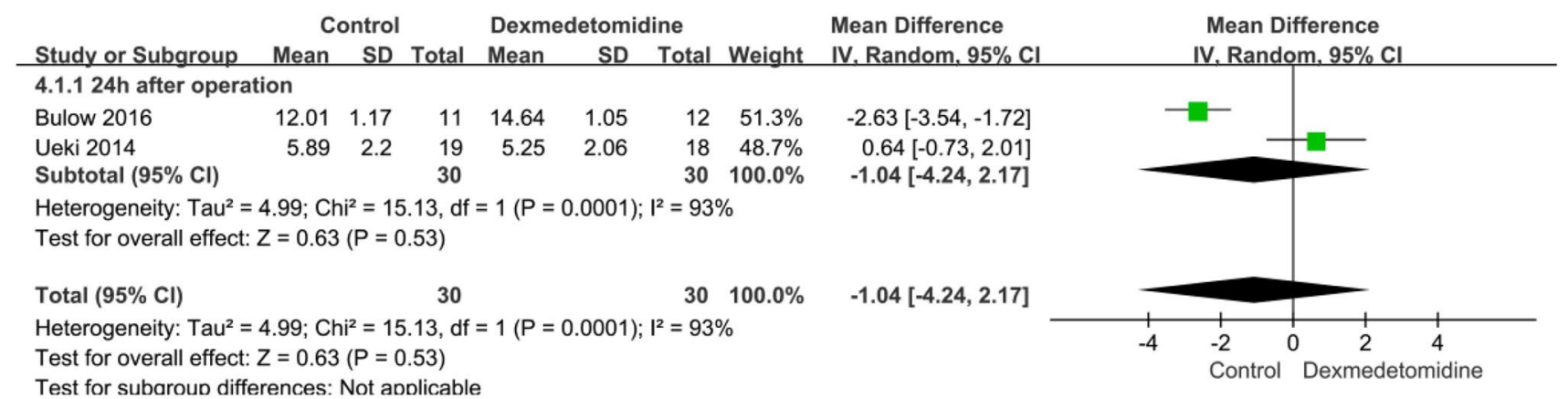

Fig. 7 CRP levels

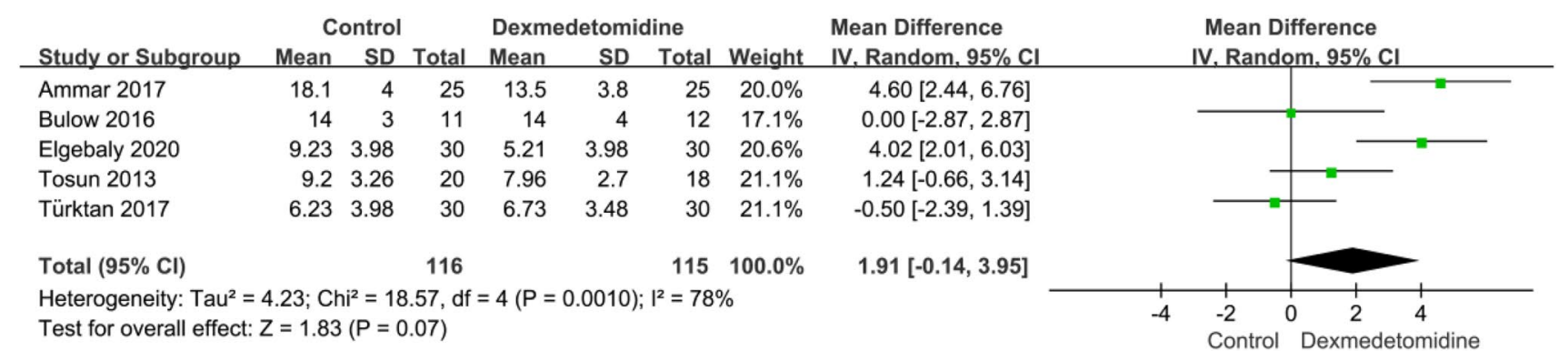

Fig. 8 The time on ventilator 


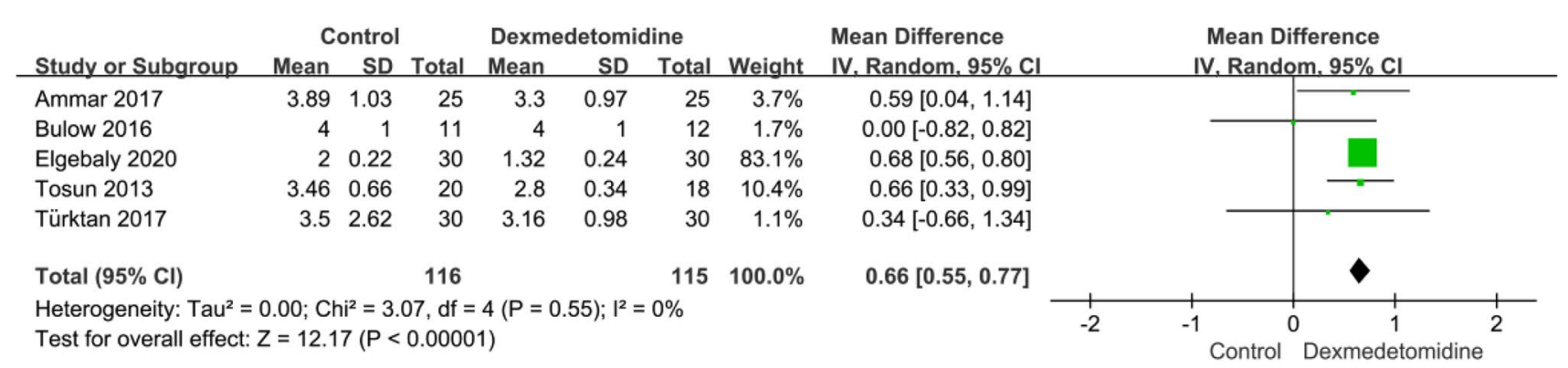

Fig. 9 The length of ICU stay

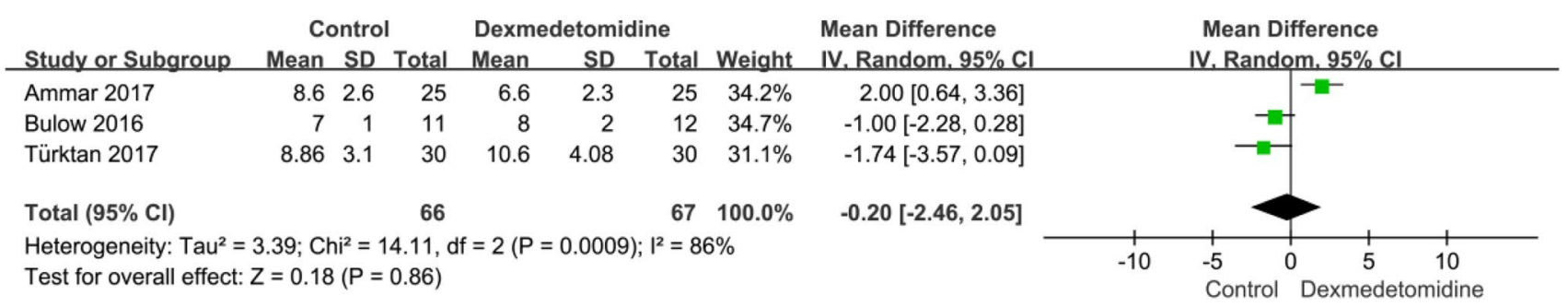

Fig. 10 The length of hospital stay

Fig. 11 Risk of bias graph

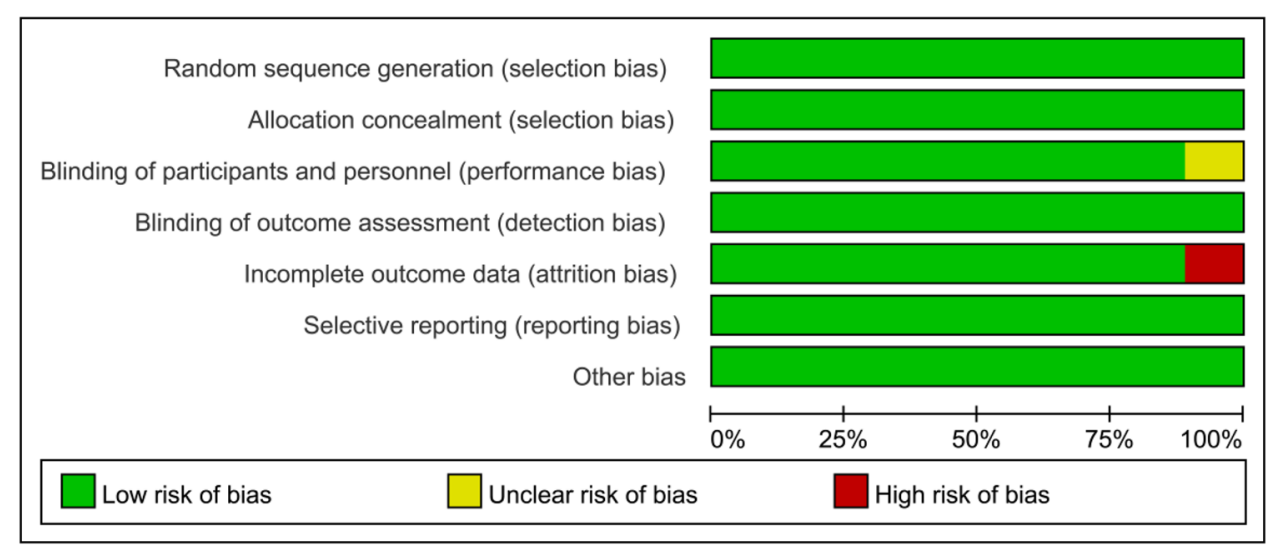

difference in anti-inflammatory cytokine IL-10 between the two groups. In addition, related meta-analysis has previously shown that dexmedetomidine can also significantly reduce the levels of IL- 6 , IL- 8 and TNF- $\alpha$ during routine general anesthesia [25]. The mechanism of dexmedetomidine in reducing inflammation may be closely related to the inhibition of NF- $\kappa B$ pathway and Toll-like receptor [15, 26-29]. Reducing the degree of inflammation may be beneficial to the rehabilitation of patients, because some studies have shown that the occurrence of inflammation is associated with adverse cardiac outcomes [30, 31].
Dexmedetomidine shortened the length of ICU stay, which suggested that dexmedetomidine perhaps can promote the rapid recovery of cardiac function in patients. However, no significant difference was found in the length of hospital stay between two groups, which may indicate that the longterm rehabilitation promoting effect of dexmedetomidine on patients undergoing $\mathrm{CPB}$ surgery is not clear. 
Fig. 12 Funnel plot

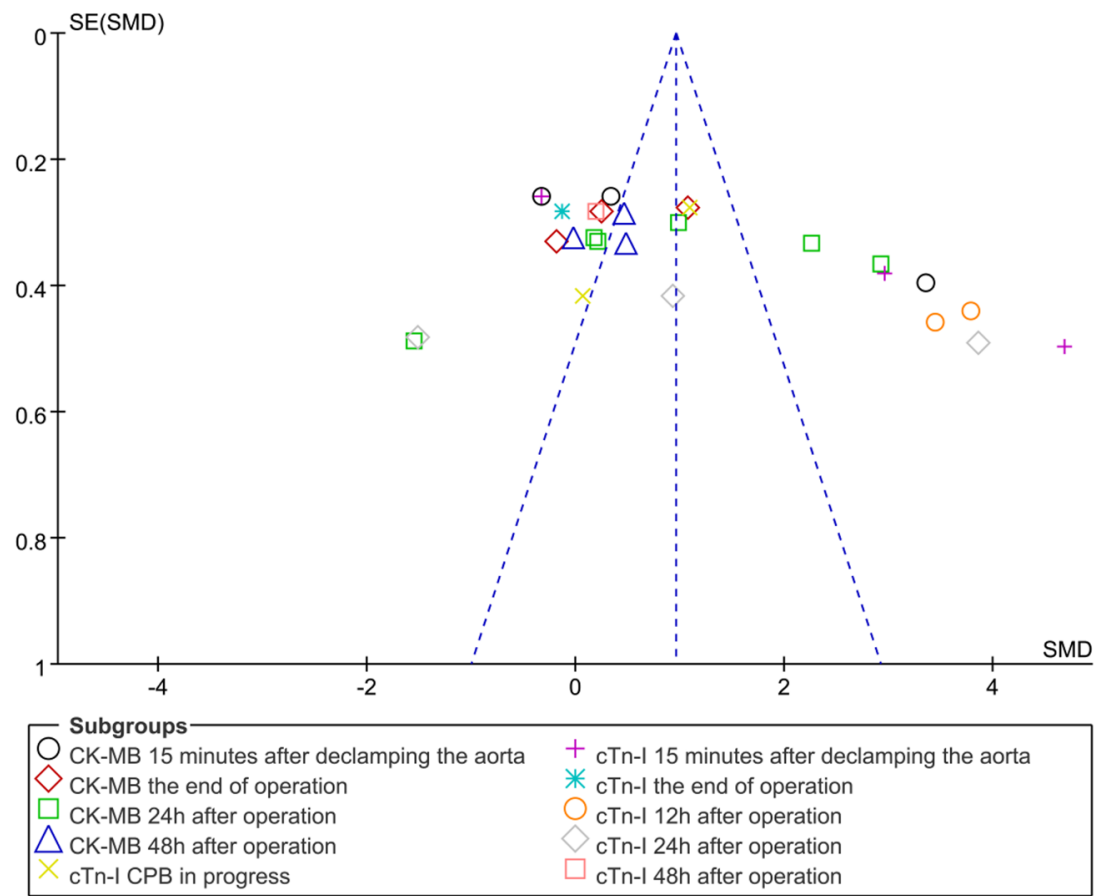

\section{Conclusion}

The administration of dexmedetomidine during CPB can provide myocardial protection by inhibiting inflammation, which may be beneficial to the rapid recovery of patients. However, further studies are needed to explore the effect of dexmedetomidine on the long-term prognosis of patients.

Supplementary Information The online version contains supplementary material available at https://doi.org/10.1007/s00540-021-02982-0.

Author contributions MLC and XL contributed to the articles screening, data synthesis and data collection. GM contributed to the study design and preparation of the primary manuscript. MLC contributed to the edited of this article.

\section{Declarations}

All authors declaring that they have read and accept the "Terms and Conditions for Anaesthesia and Intensive Care Submissions".

\section{References}

1. Madhavan S, Chan SP, Tan WC, Eng J, Li B, Luo HD, Teoh LK. Cardiopulmonary bypass time: every minute counts. J Cardiovasc Surg (Torino). 2018;59(2):274-81.

2. Tosun Z, Baktir M, Kahraman HC, Baskol G, Guler G, Boyaci A. Does dexmedetomidine provide cardioprotection in coronary artery bypass grafting with cardiopulmonary bypass? A pilot study. J Cardiothorac Vasc Anesth. 2013;27(4):710-5.

3. Mentzer RM Jr. Myocardial protection in heart surgery. J Cardiovasc Pharmacol Ther. 2011;16(3-4):290-7.
4. Kinoshita T, Asai T. Preservation of myocardium during coronary artery bypass surgery. Curr Cardiol Rep. 2012;14(4):418-23.

5. Nicolini F, Beghi C, Muscari C, Agostinelli A, Maria Budillon A, Spaggiari I, Gherli T. Myocardial protection in adult cardiac surgery: current options and future challenges. Eur J Cardiothorac Surg. 2003;24(6):986-93.

6. Schwartz LI, Twite M, Gulack B, Hill K, Kim S, Vener DF. The perioperative use of dexmedetomidine in pediatric patients with congenital heart disease: an analysis from the congenital cardiac anesthesia society-society of thoracic surgeons congenital heart disease database. Anesth Analg. 2016;123(3):715-21.

7. Ueki M, Kawasaki T, Habe K, Hamada K, Kawasaki C, Sata T. The effects of dexmedetomidine on inflammatory mediators after cardiopulmonary bypass. Anaesthesia. 2014;69(7):693-700.

8. Lempiäinen J, Finckenberg P, Mervaala EE, Storvik M, Kaivola J, Lindstedt K, Levijoki J, Mervaala EM. Dexmedetomidine preconditioning ameliorates kidney ischemia-reperfusion injury. Pharmacol Res Perspect. 2014;2(3):e00045.

9. Elgebaly AS, Fathy SM, Sallam AA, Elbarbary Y. Cardioprotective effects of propofol-dexmedetomidine in open-heart surgery: a prospective double-blind study. Ann Card Anaesth. 2020;23(2):134-41.

10. Türktan M, Güneş Y, Yalınız H, Matyar S, Hatipoğlu Z, Güleç E, Göçen U, Atalay A. Comparison of the cardioprotective effects of dexmedetomidineand remifentanil in cardiac surgery. Turk J Med Sci. 2017;47(5):1403-9.

11. Gong Z, Ma L, Zhong YL, Li J, Lv J, Xie YB. Myocardial protective effects of dexmedetomidine in patients undergoing cardiac surgery: a meta-analysis and systematic review. Exp Ther Med. 2017;13(5):2355-61.

12. Moher D, Liberati A, Tetzlaff J, Altman DG, PRISMA Group. Preferred reporting items for systematic reviews and meta-analyses: the PRISMA statement. BMJ. 2009;339:b2535.

13. Ammar AS, Mahmoud KM, Kasemy ZA, Helwa MA. Cardiac and renal protective effects of dexmedetomidine in 
cardiac surgeries: a randomized controlled trial. Saudi J Anaesth. 2016;10(4):395-401.

14. Bulow NM, Colpo E, Pereira RP, Correa EF, Waczuk EP, Duarte MF, Rocha JB. Dexmedetomidine decreases the inflammatory response to myocardial surgery under mini-cardiopulmonary bypass. Braz J Med Biol Res. 2016;49(4):e4646.

15. Chen S, Hua F, Lu J, Jiang Y, Tang Y, Tao L, Zou B, Wu Q. Effect of dexmedetomidine on myocardial ischemia-reperfusion injury. Int J Clin Exp Med. 2015;8(11):21166-72.

16. Wang L, Wang S, Xing Z, Li F, Teng J, Jia T. Application of dexmedetomidine in cardiopulmonary bypass prefilling. Dose Response. 2020;18(3):1559325820939764.

17. Zhou H, Zhou D, Lu J, Wu C, Zhu Z. Effects of pre-cardiopulmonary bypass administration of dexmedetomidine on cardiac injuries and the inflammatory response in valve replacement surgery with a sevoflurane postconditioning protocol: a pilot study. J Cardiovasc Pharmacol. 2019;74(2):91-7.

18. Chen RM, Wu CH, Chang HC, Wu GJ, Lin YL, Sheu JR, Chen TL. Propofol suppresses macrophage functions and modulates mitochondrial membrane potential and cellular adenosine triphosphate synthesis. Anesthesiology. 2003;98(5):1178-85.

19. Carden DL, Granger DN. Pathophysiology of ischaemia-reperfusion injury. J Pathol. 2000;190(3):255-66.

20. Liu YE, Tong CC, Zhang YB, Jin HX, Gao Y, Hou MX. Effect of dexmedetomidine on rats with renal ischemia-reperfusion injury and the expression of tight junction protein in kidney. Int J Clin Exp Med. 2015;8(10):18751-7.

21. Gu J, Sun P, Zhao H, Watts HR, Sanders RD, Terrando N, Xia P, Maze M, Ma D. Dexmedetomidine provides renoprotection against ischemia-reperfusion injury in mice. Crit Care. 2011;15(3):R153.

22. Cui J, Zhao H, Yi B, Zeng J, Lu K, Ma D. Dexmedetomidine attenuates bilirubin-induced lung alveolar epithelial cell death in vitro and in vivo. Crit Care Med. 2015;43(9):e356-68.

23. Koh TW, Carr-White GS, DeSouza AC, Ferdinand FD, Hooper J, Kemp M, Gibson DG, Pepper JR. Intraoperative cardiac troponin $\mathrm{T}$ release and lactate metabolism during coronary artery surgery: comparison of beating heart with conventional coronary artery surgery with cardiopulmonary bypass. Heart. 1999;81(5):495-500.
24. Ren J, Zhang H, Huang L, Liu Y, Liu F, Dong Z. Protective effect of dexmedetomidine in coronary artery bypass grafting surgery. Exp Ther Med. 2013;6(2):497-502.

25. Li B, Li Y, Tian S, Wang H, Wu H, Zhang A, Gao C. Antiinflammatory effects of perioperative dexmedetomidine administered as an adjunct to general anesthesia: a meta-analysis. Sci Rep. 2015;5:12342.

26. Zhang X, Yan F, Feng J, Qian H, Cheng Z, Yang Q, Wu Y, Zhao $\mathrm{Z}$, Li A, Xiao H. Dexmedetomidine inhibits inflammatory reaction in the hippocampus of septic rats by suppressing NF- $\mathrm{kB}$ pathway. PLoS ONE. 2018;13(5):e0196897.

27. Wang WG, Wang L, Jiao ZH, Xue B, Xu ZW. Locomotor activity of rats with SCI is improved by dexmedetomidine by targeting the expression of inflammatory factors. Mol Med Rep. 2018;18(1):415-20.

28. Liu Y, Liu W, Wang X, Wan Z, Liu Y, Leng Y. Dexmedetomidine relieves acute inflammatory visceral pain in rats through the ERK pathway, toll-like receptor signaling, and TRPV1 channel. J Mol Neurosci. 2018;66(2):279-90.

29. Chen H, Sun X, Yang X, Hou Y, Yu X, Wang Y, Wu J, Liu D, Wang H, Yu J, Yi W. Dexmedetomidine reduces ventilatorinduced lung injury (VILI) by inhibiting Toll-like receptor 4 (TLR4)/nuclear factor (NF)- $\mathrm{KB}$ signaling pathway. Bosn J Basic Med Sci. 2018;18(2):162-9.

30. Kilic T, Ural D, Ural E, Yumuk Z, Agacdiken A, Sahin T, Kahraman G, Kozdag G, Vural A, Komsuoglu B. Relation between proinflammatory to anti-inflammatory cytokine ratios and longterm prognosis in patients with non-ST elevation acute coronary syndrome. Heart. 2006;92(8):1041-6.

31. Biswas S, Ghoshal PK, Mandal SC, Mandal N. Relation of anti- to pro-inflammatory cytokine ratios with acute myocardial infarction. Korean J Intern Med. 2010;25(1):44-50.

Publisher's Note Springer Nature remains neutral with regard to jurisdictional claims in published maps and institutional affiliations. 